\title{
Lattice Constants of Titanomagnetites at High Temperatures
}

\author{
Yozo HAMANO \\ Earthquake Research Institute, University of Tokyo, Tokyo 113, Japan
}

(Received May 11, 1988; Revised July 4, 1988)

\begin{abstract}
Lattice parameter measurements were made at high temperatures of up to $700^{\circ} \mathrm{C}$ on synthetic titanomagnetite samples with $x$ values of $0.0,0.3,0.7$, and 1.0 . A high temperature $\mathrm{X}$-ray camera was used for the measurement, where heating was made in vacuum. The variation of the lattice constants of the titanomagnetite series $(x=0.0-1.0)$ can be approximated as $d[\mathrm{~A}]=\left(8.395+8.5 \times 10^{-5} T\left[{ }^{\circ} \mathrm{C}\right]+7.5 \times 10^{-8} T^{2}\right)+$ $\left(0.14-6.0 \times 10^{-5} T\right) x$, which can be used to identify the chemical change of titanomagnetites and titanomaghemites during the heating of synthetic and natural samples.
\end{abstract}

\section{Introduction}

In most terrestrial rocks, titanomagnetite solid solutions, $(1-x) \mathrm{Fe}_{3} \mathrm{O}_{4} x \mathrm{Fe}_{2} \mathrm{TiO}_{4}$, are the dominant magnetic minerals, where the mole fraction of the ulvöspinel, $x$, depends on rock types. Oxygen fugacity, temperature, and chemical composition during the formation of rocks determine the composition of the titanomagnetites. After formation, the titanomagnetites may alter to secondary products. At low temperatures of less than $300^{\circ} \mathrm{C}$ with the existence of water, titanomagnetite oxidizes to titanomaghemite, which is a non-stoichiometric cation deficient spinel phase. The titanomaghemites are commonly observed in oceanic basalts and are considered to be responsible for the linear magnetic anomalies in the oceanic crust.

Previous investigations on titanomaghemites in oceanic basalts aimed to obtain the magnetic properties (Curie temperature $T_{\mathrm{c}}$, saturation magnetization $J_{\mathrm{s}}$, etc.) and the crystallographic parameter (lattice constant, $d$ ), the oxidation condition, and the remanence properties of the low-temperature oxidized phase (IRVING, 1970; OZIMA and OZIMA, 1971; MARSHALL, 1978; HAMANO et al., 1980). To identify the composition and the oxidation stage of titanomagnetites and titanomaghemites in rocks, measurements of Curie temperature and lattice parameter have been commonly used. These parameters $\left(T_{\mathrm{c}}\right.$ and $\left.d\right)$ for synthesized titanomaghemites were investigated by OzIMA and SAKAMOTO (1971), READMAN and O'REILLY (1972), KEEFER and SHIVE (1981) and NiShITANI and Kono (1983), which all give significantly different results. This situation is very unfortunate, since we must choose one of them to determine the composition and the oxidation stage of titanomaghemites in natural rocks. Difference in the grain size, the technique for synthesizing the starting material, the inhomogeneous oxidation, and the method 
for estimating the oxidation stage have been noted to explain the difference (KeEFER and Shive, 1981; Nishitani and Kono, 1983). But, these do not totally clarify the reason for the discrepancy.

As noted by KEEFER and SHIVE (1981), most of the divergence of the above results come from the differences in Curie temperatures. Titanomaghemites are thermally unstable, and some chemical changes occur during the Curie temperature measurements, even when the heating is made in vacuum. Hence, thermomagnetic curves of titanomaghemites are generally irreversible. The change commonly observed during the heating is the unmixing of titanomaghemite to a mixture of Ti-poor titanomagnetite and ilmeno-hematite. For determination of the Curie temperature of the titanomaghemite, we have to use the unaltered part of the thermomagnetic curve. However, it is very difficult to detect the onset temperature of the unmixing from the thermomagnetic analysis. Even if the temperature is known, Curie temperature can not be precisely determined when the unmixing occurs before reaching the Curie temperature.

This situation will be improved if the lattice parameters of titanomaghemites are measured at high temperatures. The measurement can detect the unmixing of the titanomaghemite during the heating. To do this, we have to know the lattice parameters of stoichiometric titanomagnetites as a first step. The lattice parameters for magnetite have been investigated for powder and natural crystal samples (see the compilations by SKINNER (1966) and ToulOUKIAN et al. (1977). But, high temperature measurements of the lattice constants for titanomagnetite solid solutions are not available. In the present study, the lattice parameters for the titanomagnetites with $x=0.0,0.3,0.7$ and 1.0 are measured by a high temperature X-ray camera method.

\section{Experimental Procedure}

The synthesized titanomagnetite powders were prepared by the same method described by NISHITANI and KonO (1983), where the mixture of pure $\mathrm{TiO}_{2}$ and $\mathrm{FeO}_{3}$ powders in stoichiometric proportions were used as starting material and the synthesis was made by keeping the sample for several hours at $1200^{\circ} \mathrm{C}$ in a controlled oxygen fugacity. After the synthesis, the sintered sample was ground with an agate mortar. The average size of the ground samples was about several tens of micrometers. For the present study, titanomagnetites with $x$ values of 0.0 (magnetite), 0.3, 0.7, and 1.0 (ulvöspinel) were employed.

The measurements of the lattice parameters at high temperatures were made with a continuous high temperature X-ray camera made by Rigaku Denki Co. The apparatus is schematically shown in Fig. 1. For the measurement, sample powder was spread around a thin platinum wire $(0.2 \mathrm{~mm}$ in diameter) by using a glue (collodion). In each measurement, the required sample powder was less than $2 \mathrm{mg}$ in weight. The temperature during the measurements was controlled by the thermocouple shown in the figure. However, the diffracted peaks from the platinum wire, which were recorded on the same film as the sample diffraction peaks, were used to 


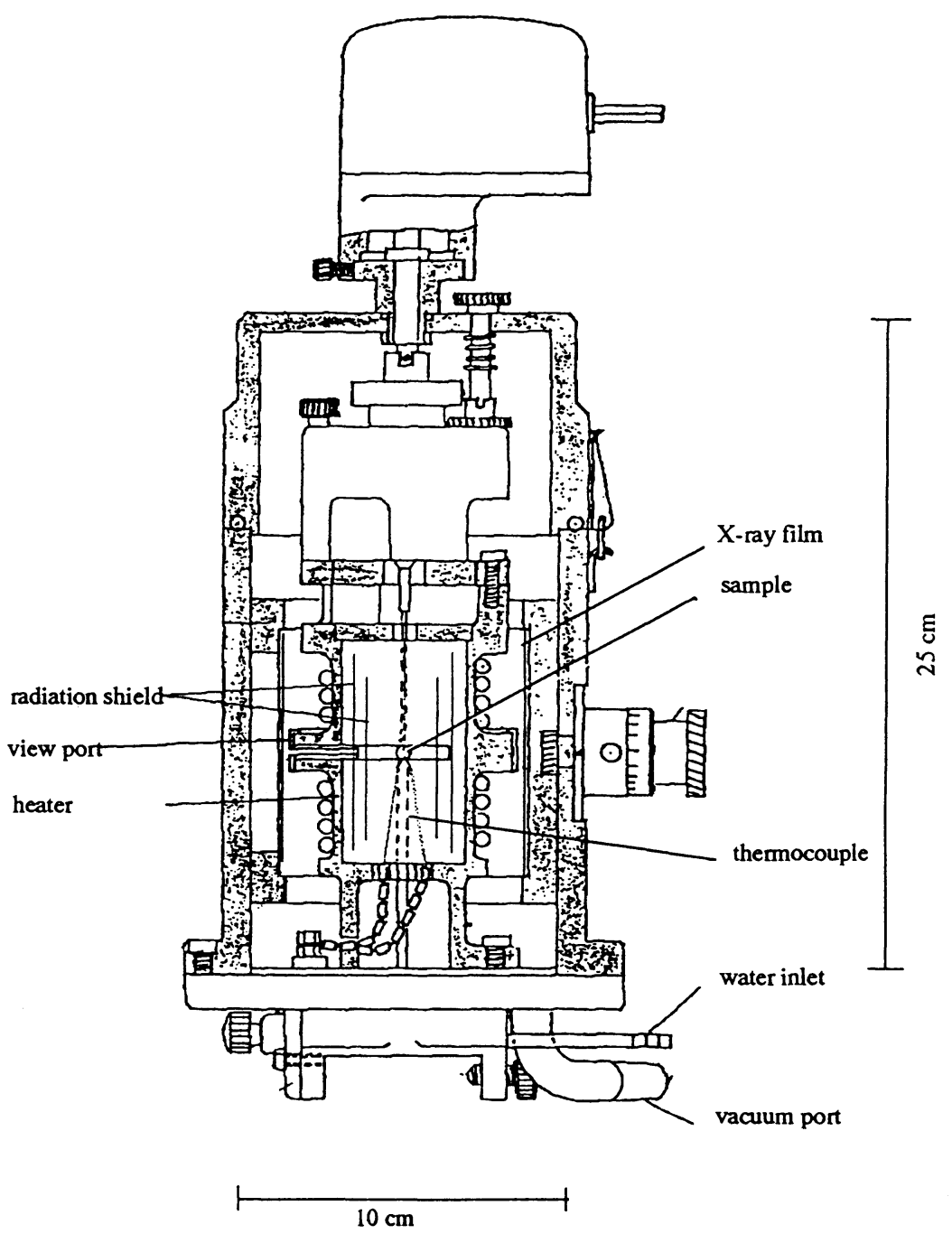

Fig. 1. Schematic view of the High Temperature X-ray Camera.

determine the lattice constant of platinum and then to estimate the exact temperature at the sample position. Figure 2 shows the difference between the temperature given by the thermocouple and that obtained from the lattice constants of the platinum, where the thermal expansion of platinum tabulated in TOULOUKIAN et al. (1975) was used to determine the temperature. As is evident from the figure, the difference is large at low temperatures due to the temperature gradient within the furnace. The data in this figure contains the results of the several runs of the measurements. Hence, Fig. 2 also indicates the reproducibility of the temperature 


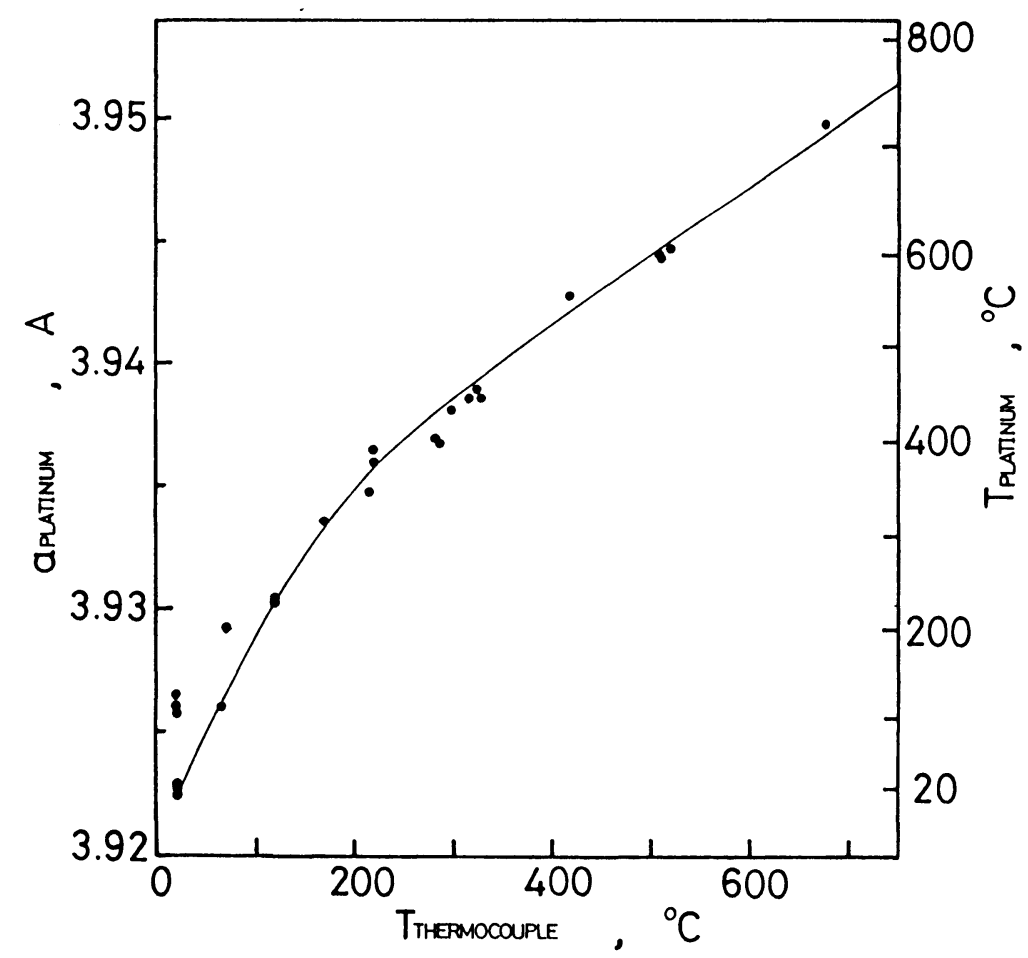

Fig. 2. Comparison of the temperatures obtained by the thermocouple and that from the internal platinum standard.

control.

An Fe target was used for the X-ray source. The radiation shield shown in Fig. 1 was originally $\mathrm{Ni}$ foil with a total thickness of $0.03 \mathrm{~mm}$. To enhance the diffracted signal, the radiation shield was replaced by Fe foil with a thickness of $0.014 \mathrm{~mm}$. Theoretically, the intensity of the signal at the film position becomes about 5 times stronger than before. The sharpness of the diffracted peaks was much improved by this replacement. The exposure time for the measurements was determined by the method of trial and error. Finally, about 45 minutes of exposure time at a source condition of $35 \mathrm{KV}$ and $20 \mathrm{~mA}$ was adopted.

In the measurements, up to eight runs at different temperatures were recorded on the same film, which can reduce the relative error due to the eccentricity of the film. This also reduces the error caused during the reading of the position of the recorded peaks.

During measurement at high temperatures, the sample space was evacuated by a rotary vacuum pump through the port shown in Fig. 1. The vacuum pressure during the measurements was estimated as about $10^{-3}$ Torr. The chemical change of the samples during the measurement was checked by measuring the lattice constants 
at room temperature before and after the heating experiments. This measurement indicated that the observed differences of the lattice constants were within error and the chemical change of the samples during the heating could be neglected. For the complete run of each sample, it took about six hours of measurements, and the last measurement at room temperature was made in the next day to ensure that the sample was equilibrated to room temperature.

After development of the film, the position of the peaks were observed by a reading apparatus made from a magnifier and micrometer. The precision of the measurement is $0.01 \mathrm{~mm}$. About 30 peaks were measured for each step, which included peaks from both the titanomagnetite and the platinum. Several low angle peaks and high angle peaks were read in both sides of the incident direction, which give the position of the zero angle on the film and the diameter of the circle surrounded by the film. The diameter is about $90 \mathrm{~mm}$, and the position of the zero angle varies about $0.1 \mathrm{~mm}$ from the first step to the last step of the measurements.

Based on the reading of the peak positions in each step, the $d$-value of platinum was calculated from about ten peaks, and was used to estimate the temperature of the sample at that step. From about 20 peaks for the titanomagnetite samples, $d$-values were calculated, and the results were plotted as a function of $\sin ^{2} \theta$, where $2 \theta$ is the diffraction angle. As shown in Fig. 3, the $d$-values align in a straight line on this plot for the higher diffraction angles. The estimate of $d$-values was obtained by extrapolation of the straight line fitted for the high angle part of the data to the high angle limit $\left(2 \theta=180^{\circ}\right)$. The straight lines were determined by the least squares method, and the intersect and the estimated error of the intersect were calculated. This procedure minimizes systematic errors due to the eccentricity of the sample position and the effect of the absorption of X-ray by the specimen (CULLITY, 1956). Another method for the precise determination of the lattice constant uses a standard specimen for the calibration of the diffracted angles. However, this method was not employed in the present measurement, since the diffracted peaks from three crystals (platinum, titanomagnetite and a standard sample) will be obscured on the film.

\section{Results}

The results of the measurements are summarized in Table 1 and shown in Fig. 4. The temperature of the samples was estimated from the lattice constants of platinum, except for the first room temperature measurement before heating. At the measurement for each sample, the observed lattice constant of platinum was around $3.926 \mathrm{~A}$, which is systematically larger than the assigned room temperature value of 3.9226 A. Since the room temperature measurements after the heating give lattice constants of platinum very close to the assigned value, this result is not due to the impurity of the platinum. Internal strain in the platinum wire arising from the initial setting of the specimen could be a possible cause of this discrepancy. After the heating, the internal strain might be relaxed. We did not use the first measurement of the platinum lattice constants for the temperature estimate, because we know the exact temperature of the sample. 


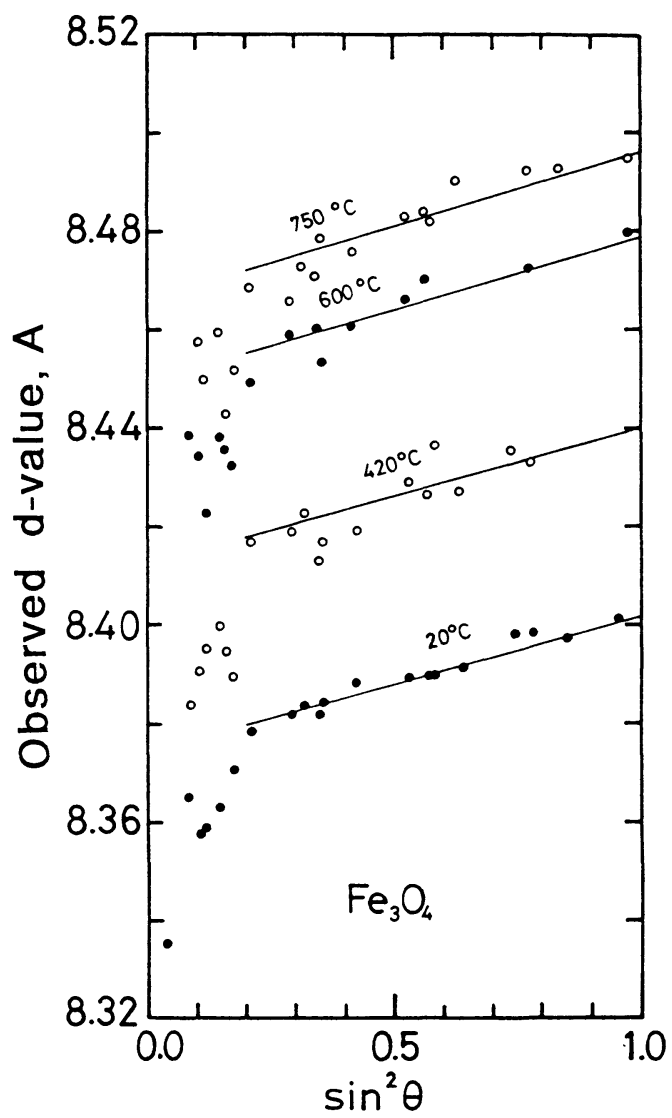

Fig. 3. Plot of the observed $d$-values for pure magnetite as a function of $\sin _{2} \theta$. Measurements at the temperatures of $20^{\circ} \mathrm{C}, 420^{\circ} \mathrm{C}, 600^{\circ} \mathrm{C}$ and $750^{\circ} \mathrm{C}$ are shown.

The room temperature values for the titanomagnetite samples were also measured before and after heating, except for the ulvöspinel sample. Comparison of the two room temperature values for each sample indicates that chemical change during the heating is negligibly small. The difference of the two values is around 0.01 $\mathrm{A}$, and can be attributed to the same cause as that explained for the platinum.

The variation of the lattice constant for the titanomagnetites with an ulvöspinel content of $0.0,0.3,0.7$ and 1.0 are shown in Fig. 4. Thermal expansion of magnetite has been measured for crystal samples and powder samples (see SKINNER (1966) and TOULOUKIAN et al. (1977). These previous data were compiled and a provisional value given in TOULOUKIAN et al. (1975). The present measurement of the magnetite sample is consistent with the previous value. For other titanomagnetite samples, previous data are not available except for room temperature values.

For the temperature range of the present measurement, the nonlinearity of the 
Table 1. Results of the measurements.

\begin{tabular}{|c|c|c|}
\hline $\begin{array}{c}\text { Temperature } \\
{\left[{ }^{\circ} \mathrm{C}\right]} \\
\end{array}$ & $\begin{array}{c}\text { Lattice constant } \\
\text { platinum } \\
{[\mathrm{A}]}\end{array}$ & $\begin{array}{c}\text { Lattice constant } \\
\text { titanomagnetite } \\
\text { [A] }\end{array}$ \\
\hline \multicolumn{3}{|l|}{$x=0.0$} \\
\hline 20 & $(3.926 \pm 0.002)$ & $8.394 \pm 0.005$ \\
\hline 400 & $3.937 \pm 0.002$ & $8.440 \pm 0.003$ \\
\hline 595 & $3.944 \pm 0.001$ & $8.475 \pm 0.003$ \\
\hline 720 & $3.950 \pm 0.001$ & $8.496 \pm 0.003$ \\
\hline 20 & $3.922 \pm 0.002$ & $8.402 \pm 0.004$ \\
\hline \multicolumn{3}{|l|}{$x=0.3$} \\
\hline 20 & $(3.926 \pm 0.001)$ & $8.437 \pm 0.005$ \\
\hline 120 & $3.926 \pm 0.004$ & $8.440 \pm 0.006$ \\
\hline 225 & $3.930 \pm 0.002$ & $8.457 \pm 0.005$ \\
\hline 450 & $3.939 \pm 0.003$ & $8.479 \pm 0.006$ \\
\hline 595 & $3.944 \pm 0.002$ & $8.507 \pm 0.009$ \\
\hline 20 & $3.923 \pm 0.002$ & $8.429 \pm 0.006$ \\
\hline \multicolumn{3}{|l|}{$x=0.7$} \\
\hline 20 & $(3.927 \pm 0.002)$ & $8.507 \pm 0.006$ \\
\hline 225 & $3.930 \pm 0.003$ & $8.517 \pm 0.004$ \\
\hline 395 & $3.937 \pm 0.001$ & $8.529 \pm 0.007$ \\
\hline 460 & $3.939 \pm 0.003$ & $8.535 \pm 0.007$ \\
\hline 555 & $3.943 \pm 0.002$ & $8.545 \pm 0.005$ \\
\hline 630 & $3.946 \pm 0.007$ & $8.553 \pm 0.007$ \\
\hline 20 & $3.923 \pm 0.001$ & $8.494 \pm 0.004$ \\
\hline \multicolumn{3}{|l|}{$x=1.0$} \\
\hline 20 & $(3.926 \pm 0.002)$ & $8.537 \pm 0.007$ \\
\hline 205 & $3.929 \pm 0.003$ & $8.543 \pm 0.007$ \\
\hline 315 & $3.934 \pm 0.002$ & $8.554 \pm 0.005$ \\
\hline
\end{tabular}

thermal expansion is evident. Figure 4 also indicates that the thermal expansion coefficient decreases with the increase of $x$, i.e., the ulvöspinel content. In order to obtain the overall variation of the lattice constant with temperature and $x$, the temperature dependence of the lattice constant for each titanomagnetite sample was expressed with a second order equation of $d=d_{0}+a_{1} T\left[{ }^{\circ} \mathrm{C}\right]+a_{2} T^{2}$ by the least squares method. Then, the variation of the lattice constants with $x$ at temperatures of $20^{\circ} \mathrm{C}, 200^{\circ} \mathrm{C}, 400^{\circ} \mathrm{C}$ and $600^{\circ} \mathrm{C}$ were approximated by a straight line, and the gradient of the line was obtained. By the above procedure, the overall variation of the lattice constants with $T$ and $x$ has been expressed as

$$
d=\left(8.395+8.5 \times 10^{-5} T+7.5 \times 10^{-8} T^{2}\right)+\left(0.140-6 \times 10^{-5} T\right) x,
$$

where the lattice constant, $d$, is given by a unit of $\mathrm{A}$ and the temperature, $T$, is 


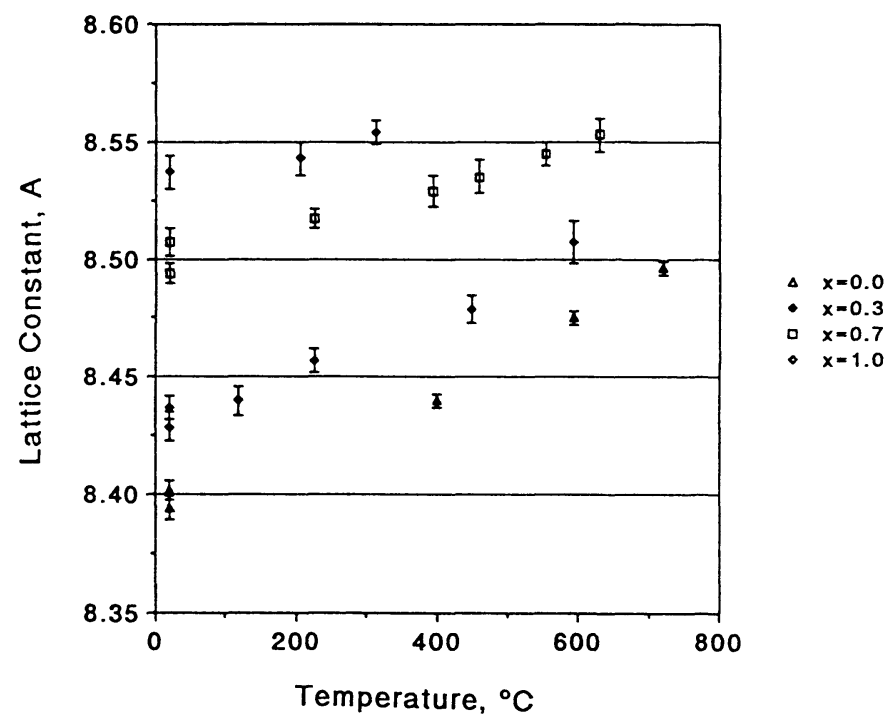

Fig. 4. Observed variation of the lattice constants as a function of temperature for the titanomagnetites with $x=0.0,0.3,0.7$, and 1.0 .

expressed by Centigrade. The variation of the lattice constant given by the above equation is shown in Fig. 5 (as a function of $T$ ) and Fig. 6 (as a function of $x$ ) with the observed values. Although the equation is a rough estimate, it well approximates the observe variation. Hence, this equation can be used to approximate the variation of the lattice constant for the titanomagnetite solid solutions as a function of $T$ and $x$.

\section{Discussion}

The primary purpose of the present paper was to provide lattice constant data at high temperatures for stoichiometric titanomagnetite solid solutions, such as shown in Fig. 5. This data can be used to identify the titanomagnetite under high temperature conditions. Moreover, the data are useful for the investigation of lowtemperature oxidized titanomaghemites. As noted above, the lattice constants and Curie temperatures for the titanomaghemites were given so far by four groups, where all of them gave different results. For the titanomaghemite, the estimate of Curie temperature causes some difficulty, since the titanomaghemite is thermally unstable, and their thermomagnetic curves are irreversible. The irreversible thermomagnetic curves are caused by the unmixing of titanomaghemites into Ti-poor titanomagnetite and ilmenite when the samples are heated. The onset temperature of the unmixing depends on grain size, $x$-values and the oxidation stage, and is very difficult to identity from the thermomagnetic curves. If we can detect any chemical 


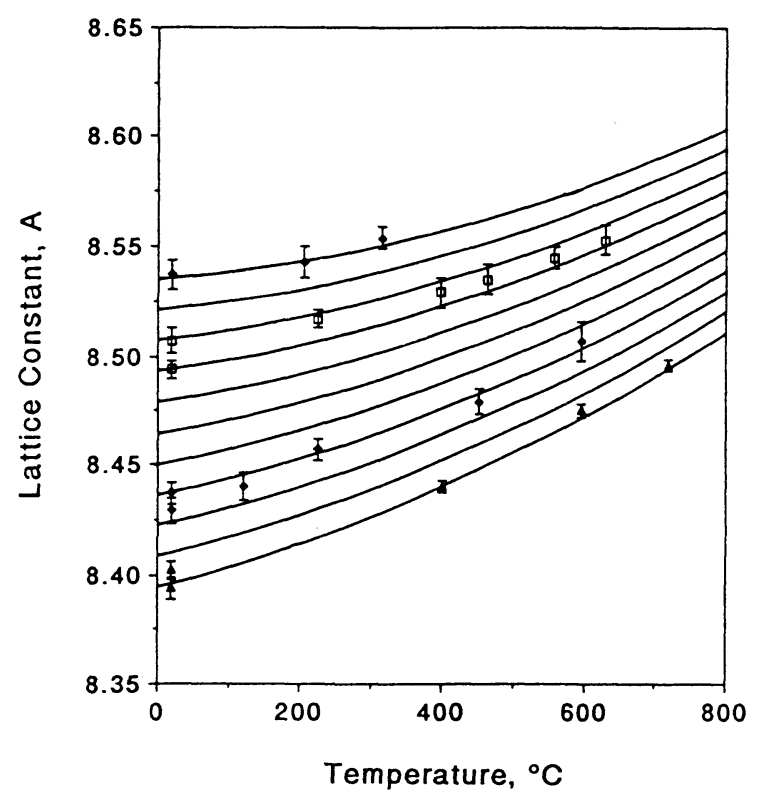

Fig. 5. Temperature variation of the lattice constants for the titanomagnetite solid solutions calculated from the model shown in the text. Curves are for the titanomagnetites from $x=0.0$ to $x=1.0$ with 0.1 increments. Experimental results are also indicated for comparison, where the symbols are the same as in Fig. 4.

change during the heating, the reliability of the Curie temperature measurements will be enhanced.

For the above purpose, the high temperature measurements of the lattice constant can be used if the lattice constant of titanomagnetites is known. Strictly speaking, we should know the lattice constants of titanomaghemites. The present results can be used to obtain such parameters.

In order to investigate this possibility, some experiments were made. During the measurements of the lattice constants of ulvöspinel, after the measurements of the lattice constant at $315^{\circ} \mathrm{C}$ (No. 3 in Fig. 7), air was introduced into the chamber of the high temperature X-ray camera. As shown in Fig. 7, then, the lattice constant was measured at $420^{\circ} \mathrm{C}$ in air (No. 4). Figure 7 indicates that the lattice constant decreases from $8.55 \mathrm{~A}$ to $8.48 \mathrm{~A}$, though the temperature increases from $315^{\circ} \mathrm{C}$ to $420^{\circ} \mathrm{C}$. After this measurement, the apparatus was cooled to room temperature, then, Nos. 5,6 and 7 were measured by increasing temperature in vacuum. These latter three points follow the thermal expansion curve of pure magnetite. The above result can be explained by the unmixing of the ulvöspinel, when air was introduced to the chamber. 


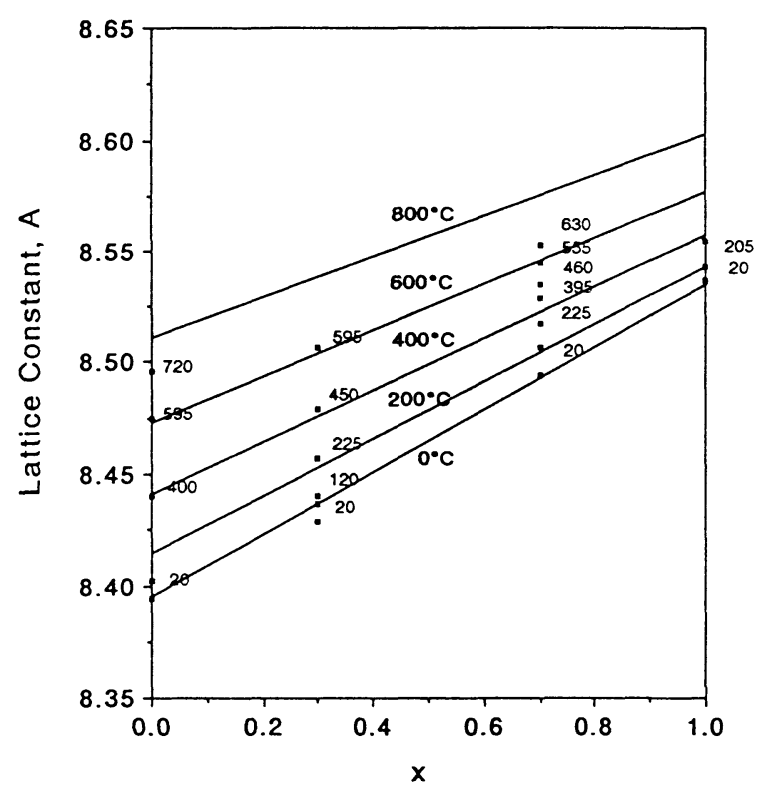

Fig. 6. Calculated variation of the lattice constants as function of $x$. Solid linea are for the temperatures of $0^{\circ} \mathrm{C}, 200^{\circ} \mathrm{C}, 400^{\circ} \mathrm{C}$ and $800^{\circ} \mathrm{C}$. Experimental results are also shown.

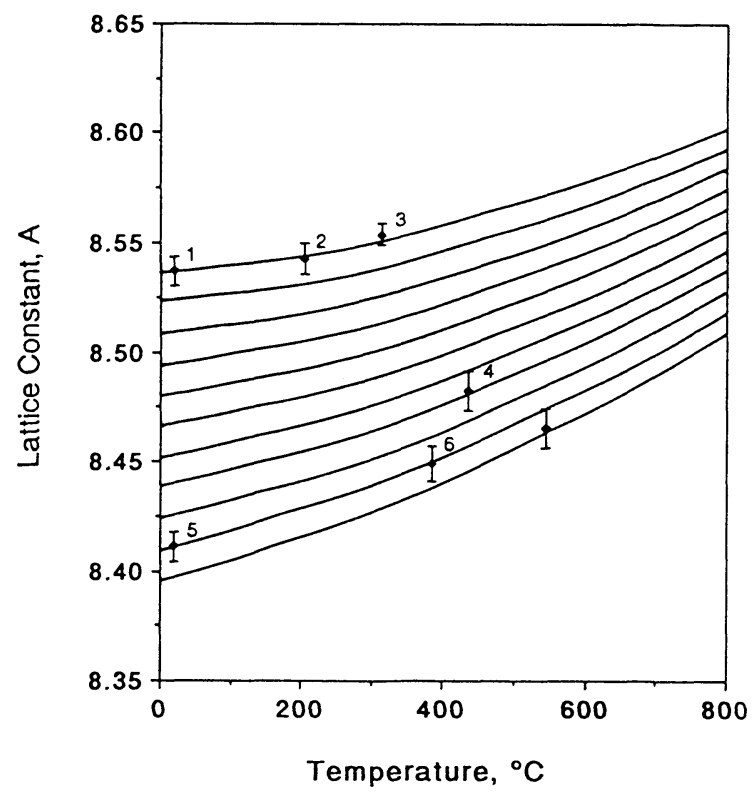

Fig. 7. Observed variation of the lattice constant of ulvöspinel $(x=1.0)$. Numbers at the symbols indicate the order of the measurements (see text). 


\section{Conclusion}

The variation of the lattice constants of the titanomagnetite solid solutions for the temperature range from room temperature to $700^{\circ} \mathrm{C}$ was estimated based on high temperature X-ray measurements. High temperature characteristics of titanomagnetites and titanomaghemites can be examined by using the present results and technique.

I with to thank Drs. T. Nishitani and T. Katsura for providing the titanomagnetite samples for the present experiment.

\section{REFERENCES}

Cullity, B. D., Elements of X-Ray Diffraction, 517pp., Addison-Wesley Pub. Co. Inc., Massachusetts, U.S.A., 1956.

Hamano, Y., T. Nishitani, and M. Kono, Magnetic properties of basalt samples from Deep Sea Drilling Project holes 417D and 418A, Init. Rep. DSDP, 51/52/53, 1391-1405, 1980.

IRving, E., The Mid-Atlantic Ridge at $45^{\circ} \mathrm{N}$. XIV Oxidation and magnetic properties of basalt; review and discussion, Can. J. Earth Sci., 7, 1528-1538, 1970

KeEFER, C. M. and P. N. Shive, Curie temperature and lattice constant reference contours for synthetic titanomagnetites, J. Geophys. Res., 86, 987-998, 1981.

Marshall, M., The magnetic properties of some DSDP basalts from the North Pacific and inference for Pacific Plate tectonics, J. Geophys. Res., 83, 289-308, 1978.

NishitANi, T. and M. Kono, Curie temperature and lattice constant of oxidized titanomagnetite, Geophys. J. R. Astr. Soc., 74, 585-600, 1983.

Ozima, M. and M. Ozima, Characteristic thermomagnetic curve in submarine basalts, J. Geophys. Res., 76, 2051-2056, 1971.

Ozima, M. and N. SaKamoto, Magnetic properties of synthesized titanomaghemite, J. Geophys. Res., 76, 7035-7046, 1971.

Readman, P. W. and W. O'Reilly, Magnetic properties of oxidized (cation deficient) titanomagnetite (Fe, $\mathrm{Ti}, \square)_{3} \mathrm{O}_{4}$, J. Geomag. Geoelectr., 24, 69-90, 1972.

Skinner, B. J., Thermal expansion, in Handbook of Physical Constants, Edited by S. P. Clark, Jr., pp. 75-96, The Geological Soc. of America, Inc., 1966.

Touloukian, Y. S., R. K. KiRbY, R. E. TAYloR, and P. D. Desal, Thermal expansion, metallic elements and alloys, Thermophys. Prop. Matter, 12, 254-259, 1975.

Touloukian, Y. S., R. K. Kirby, R. E. TAYlor, and T. Y. R. LeE, Thermal expansion, non metallic solids, Thermophys. Prop. Matter, 13, 276-281, 1977. 